\title{
Measurement of Nutrition Environments in Grocery Stores, Convenience Stores, and Restaurants in the Lower Mississippi Delta
}

\author{
Jessica L. Thomson, $\mathrm{PhD}^{1}$; Melissa H. Goodman, $\mathrm{PhD}^{1}$; Alicia S. Landry, PhD, RD, LDN, SNS ${ }^{2}$
}

\begin{abstract}
Accessible Version: www.cdc.gov/pcd/issues/2020/19_0293.htm
Suggested citation for this article: Thomson JL, Goodman MH, Landry AS. Measurement of Nutrition Environments in Grocery Stores, Convenience Stores, and Restaurants in the Lower Mississippi Delta. Prev Chronic Dis 2020;17:190293. DOI: https:// doi.org/10.5888/pcd17.190293.
\end{abstract}

\section{PEER REVIEWED}

\section{Summary}

What is already known on this topic?

The sociodemographic characteristics of the Lower Mississippi Delta population are linked to poor diet quality. Reproductive-age women residing in this region are at increased risk for adverse maternal and infant outcomes associated with suboptimal maternal nutrition.

\section{What is added by this report?}

The 5 Lower Mississippi Delta towns included in this study scored low on nutrition environment measures associated with healthful eating.

What are the implications for public health practice?

Assessment of nutrition environments before conducting dietary interventions in rural communities is necessary to first ascertain the presence of environmental supports that facilitate healthful eating.

\section{Abstract}

\section{Introduction}

The Lower Mississippi Delta is characterized by several factors associated with poor diet quality. Our objective was to measure local nutrition environments of pregnant women and their infants who participated in a nutrition and physical activity intervention to assess environmental exposures potentially influencing their dietary habits.

\section{Methods}

We measured the nutrition environments of 5 towns in which participants resided by using the Nutrition Environment Measures
Survey for grocery stores, convenience stores, full-service restaurants, and fast food restaurants. We used general linear models to test for differences in ratio scores, calculated by dividing each food outlet score by the maximum score possible, among food outlet classes and subclasses.

\section{Results}

Mean total ratio scores (expressed as percentages) for the Nutrition Environment Measures Survey among 4 classes of food outlets were significantly different from one another except for convenience stores and full-service restaurants. On average, grocery stores $(n=11)$ had $54 \%$ of maximum points possible, followed by full-service restaurants $(21 \% ; n=50)$, convenience stores $(16 \% ; n$ $=86)$, and fast food restaurants $(8 \% ; n=119)$. We found no significant differences in mean total ratio scores among convenience store subclasses. For fast food restaurant subclasses, stand-alone restaurants $(n=81)$ had $19 \%$ of maximum points possible, significantly higher than grocery store delicatessens $(6 \% ; n=8)$, corner stores that sold fast food $(3 \% ; n=5)$, and gas stations that sold fast food $(4 \% ; n=25)$.

\section{Conclusion}

These 5 Lower Mississippi Delta towns scored low on nutrition environment measures associated with healthful eating. Behavioral interventions designed to bring about positive changes in dietary habits of rural residents are needed; however, effects may be minimal if environmental factors supportive of healthful eating are not available.

\section{Introduction}

The Mississippi River Delta region is among the most socioeconomically disadvantaged areas of the United States; the region has poorer health outcomes than non-Delta counties in the same states and the nation (1). Furthermore, counties in the Delta region have lower scores for factors contributing to a healthy food environment (eg, access to healthy foods, food security) than either nonDelta counties or the nation (1). Compounding these circum- 
stances, reproductive-age women residing in this region are at increased risk for adverse outcomes associated with suboptimal maternal nutrition $(2,3)$, including maternal and infant mortality, preterm birth, and low infant birth weight $(4,5)$. For optimal health, consuming nutritious foods is essential to prevent and ameliorate nutrition-related health conditions, such as obesity, type 2 diabetes, and cardiovascular disease (6). Accessibility (the location of healthful food outlets near neighborhoods, particularly neighborhoods in low-income or rural areas), availability (healthful options in local food outlets), and affordability (reasonable prices) of nutrient-dense food resources are essential to facilitate adoption of a healthful diet (7-9).

From March 2013 through May 2016, we conducted the Delta Healthy Sprouts Project among pregnant women and their infants residing in the rural Lower Mississippi Delta. We designed the project to compare the effect of 2 maternal, infant, and early childhood home visiting curricula on health behaviors of women and their infants (10). Despite the project's focus on nutrition intervention, early results indicated that the women's baseline diet quality was poor and did not improve in either the gestational or postnatal periods $(11,12)$. These results were concerning because the women's unhealthy dietary habits may have adversely affected their infants' dietary intake (13). Therefore, we conducted an exploratory ancillary investigation, the Delta Food Outlets Study, to measure local nutrition environments to which these women and their infants were exposed to assess environmental exposures potentially influencing their dietary habits. Such information is important to inform future nutrition interventions conducted in the same region of the country with similar populations.

\section{Methods}

\section{Study setting}

The Delta Food Outlets Study was an observational ancillary study to the Delta Healthy Sprouts Project; the ancillary study collected data on food outlets in 5 towns in which Delta Healthy Sprouts participants resided. The study was approved and classified as exempt by the institutional review board of Delta State University. Data collection occurred from March 2016 through September 2018.

\section{Food outlet identification and classification}

We identified grocery stores by referencing 2 sources: the US Department of Agriculture (USDA) Food and Nutrition Service Supplemental Nutrition Assistance Program (SNAP) retailer locator (14), which lists SNAP retailers by state and location, and the Mississippi State Department of Health Restaurant and Food Facility Inspections website (15). We identified convenience stores by ref- erencing 3 sources: the SNAP retailer locator (14); the B2B Yellow Pages website (16), which provides a search engine for business type and city/state location; and lists of current privilege licenses (licenses allowing a person to do business in the city for a profit) obtained from city clerks. Restaurants, which cannot operate without a current license and passing an annual inspection, were identified by referencing the Mississippi State Department of Health Restaurant and Food Facility Inspections website (15).

We classified food outlets by using operational definitions provided by the Economic Research Service in the documentation of its Food Environment Atlas (17). Briefly, grocery stores were defined as supermarkets and smaller grocery stores primarily engaged in retailing a general line of food, such as canned and frozen foods; fresh fruits and vegetables; and fresh and prepared meats, fish, and poultry. Convenience stores were defined as stores primarily engaged in retailing a limited line of goods that generally includes milk, bread, soda, and snacks. Full-service restaurants were defined as restaurants that provide food service to patrons who order and are served while seated and pay after eating. Fast food restaurants were defined as restaurants that provide food services (excluding snack and nonalcoholic beverage bars) where patrons generally order or select items and pay before eating. We further subclassified convenience stores as gas stations, national chain dollar stores (Dollar General, Dollar Tree, Family Dollar, and Fred's), national chain pharmacies (CVS Pharmacy, Walgreens, and Getwell Drug and Dollar) or corner stores (all others). In addition to stand-alone chain restaurants and local fast food restaurants, grocery stores selling fast food (delicatessens), corner stores selling fast food, and gas stations selling fast food also were classified as fast food restaurants. Hence, grocery stores, corner stores, and gas stations selling fast food were measured twice: first to capture data on the nutritional aspects of the store environment and second to capture data on the nutritional aspects of the fast food environment. Before measurement, we visited all identified outlets to ensure that they were open and sold food.

\section{Measures}

We measured the nutrition environments of food outlets by using the Nutrition Environment Measures Survey (NEMS) for grocery stores (NEMS-S), convenience stores (NEMS-CS), and restaurants (NEMS-R) (18). NEMS-S is a validated observational measure of retail store nutrition environments; it focuses on the availability of healthful food choices and quality fresh produce and compares the price of healthful options with the price of less healthful options in 11 common categories (19). NEMS-CS expanded NEMS-S to include additional measures for frozen and canned fruits and vegetables and quantities of fresh produce (20). Points are awarded according to the availability of healthful or more healthful options (eg, fresh fruits and vegetables, lower-fat ground

\footnotetext{
The opinions expressed by authors contributing to this journal do not necessarily reflect the opinions of the U.S. Department of Health and Human Services, the Public Health Service, the Centers for Disease Control and Prevention, or the authors' affiliated institutions.
} 
beef), price comparisons between more healthful and less healthful options (eg, $100 \%$ fruit juice vs juice drink), and quality of fresh produce. Scores for the 3 scales - availability, price, and quality - are summed to create total scores for the NEMS-S and NEMS-CS. NEMS-R is a validated observational measure of restaurants designed to assess the relative healthfulness of foods and beverages available on main menus and children's menus; it focuses on availability, facilitators, and supports for healthful eating; barriers to healthful eating; pricing; and signage/promotion (21). For food items, points are awarded according to availability of more healthful options (eg, lower-calorie/lower-fat entrées, fruit without added sugar, nonfried vegetables without added sauce) and price comparisons between more healthful and less healthful entrées. Scores for 4 scales - healthful options, facilitators for healthful eating, barriers to healthful eating, and children's menu are summed to create the total score for NEMS-R. For this study, we did not include points for the children's menu in the total score so that all restaurants (those with and without children's menus) were measured by using the same set of scales. However, we did compare scores for children's menus at full-service and fast food restaurants. We scored food outlets by using algorithms provided for the tools; we modified the algorithms (Table 1) to reflect that water is a more healthful beverage choice than artificially sweetened soda and to decrease emphasis on some low-fat foods because they tend to have more sugar than their regular-fat counterparts (22).

Before data collection, senior researchers and research assistants (data collectors) completed a NEMS online training course, which included fieldwork, and were certified as NEMS raters (18). We recreated the NEMS tools as electronic surveys by using Snap Surveys software version 11.20 (Snap Surveys Ltd). All data were collected via tablets loaded with Snap Surveys software and stored on the Snap WebHost, an online mobile and secure survey management system. For quality assurance purposes, we randomly selected $25 \%$ of the food outlets for duplicate measurement. Discrepancies between duplicate measurements were discussed and resolved.

\section{Data analyses}

We performed statistical analyses by using SAS version 9.4 (SAS Institute Inc). To allow for comparisons among food outlet classes, we transformed NEMS scores into ratio scores by dividing each food outlet score by the maximum score possible. The use of ratio scores was necessary because each NEMS tool has a different possible score range (NEMS-S, -10 to 57 ; NEMS-CS, -9 to 57 ; NEMS-R, -7 to 27). The higher the ratio score, the more healthful the nutrition environment. We used general linear models with normal distributions and custom contrasts to test for differences in ratio scores among the food outlets. Class was modeled as a main effect, and subclass was nested within class. The NEMS-R scale was modeled with a $\beta$ distribution because ratio scores represented true proportions (ie, no negative ratios nor ratios equal to the boundaries of 0 and 1). We visually inspected residual plots to confirm that residuals were approximately normally distributed. We computed least squares means and $95 \%$ confidence intervals from the general linear models, because they are adjusted for other factors in the model and because of the unequal sample sizes in the food outlet classes and subclasses. To correct for multiple testing, we adjusted the significance level of .05 by using a Bonferroni correction factor (ie, .05 of 6 comparisons $=.008$ ).

\section{Results}

Of the 280 food outlets identified, 12 were closed ( 3 convenience stores and 9 restaurants), 1 refused to be measured (convenience store), and 1 was deemed unsafe (convenience store). The resulting analytic sample of 266 food outlets comprised 11 grocery stores, 86 convenience stores, 50 full-service restaurants, and 119 fast food restaurants (Table 2). The population of the 5 towns ranged from 1,750 to 32,612 . The percentage of population that was African American ranged from $49 \%$ to $91 \%$, and the percentage of population that lived below the federal poverty level ranged from $29 \%$ to $51 \%$. At baseline, $11 \%$ of Delta Healthy Sprouts participants had passing diet quality scores $(60 \%-72 \%$ of total points). The percentage of participants with passing scores who resided in towns with 4 or 5 grocery stores (11\%) was approximately equal to that of participants who resided in towns with 0 or 1 grocery stores $(12 \%)$.

Of 370 items analyzed in grocery stores, discrepancies in duplicate measurements ranged from 1 to 10 items $(0.3 \%-2.7 \%)$ per store; the most common discrepancy was availability of diet soda. Of 389 items examined in convenience stores, discrepancies in duplicate measurements ranged from 0 to 7 items $(0 \%-1.8 \%)$ per store; the most common discrepancy was food brand. Of 142 items examined in restaurants, discrepancies in duplicate measurements ranged from 0 to 8 items $(0 \%-5.6 \%)$ per restaurant; the most common discrepancy was hours of operation.

Mean total ratio scores for the 4 classes of food outlets were significantly different from one another except for convenience stores and full-service restaurants (Table 3 ). Grocery stores had the highest mean total ratio score $(0.54)$ followed by full-service restaurants $(0.21)$, convenience stores $(0.16)$, and fast food restaurants (0.08). We found no significant differences for mean total ratio scores among convenience store subclasses. For fast food restaurant subclasses, stand-alone restaurants had a significantly higher mean total ratio score $(0.19)$ than grocery store delicates-

The opinions expressed by authors contributing to this journal do not necessarily reflect the opinions of the U.S. Department of Health and Human Services, the Public Health Service, the Centers for Disease Control and Prevention, or the authors' affiliated institutions. 
sens (0.06), corner stores that sold fast food (0.03), and gas stations that sold fast food (0.04).

For availability and price scales, mean ratio scores for grocery stores were significantly higher than scores for convenience stores ( 0.63 vs 0.21 and 0.25 vs 0.10 , respectively). Among convenience store subclasses, mean ratio scores for the availability scale were significantly higher for national chain dollar stores and pharmacies ( 0.31 and 0.32 , respectively) than for corner stores and gas stations (0.12 and 0.13 , respectively). Mean ratio scores for the price scale were significantly higher for gas stations $(0.14)$ than for national chain dollar stores (0.05). Because so few convenience stores sold fresh fruits or fresh vegetables, we did not compare convenience stores and grocery stores for the quality scale. Descriptively, all but 1 of the 11 grocery stores received the maximum score of 6 for the quality scale, whereas the one received a score of 5 . Of the 86 convenience stores, 8 (4 corner stores and 4 gas stations) sold fresh produce; quality scores were $0(\mathrm{n}=3), 4$ (n $=4)$, and $6(\mathrm{n}=1)$. Mean (standard deviation) quality scale scores were 5.9 (0.3) for grocery stores and 2.3 (2.1) for convenience stores.

For restaurants, the mean ratio score for the healthful options scale was significantly higher for full-service restaurants $(0.32)$ than for fast food restaurants (0.13). Conversely, the mean ratio score for the children's menu scale was significantly higher for fast food restaurants (0.20) than for full-service restaurants (0). Among fast food restaurant subclasses, the mean ratio score for the healthful options scale was significantly higher for stand-alone fast food restaurants $(0.28)$ than for grocery stores with a delicatessen $(0.10)$, corner stores $(0.05)$, and gas stations $(0.08)$. For the facilitators and barriers scales, we did not find significant differences in mean ratio scores between full-service restaurants and fast food restaurants and among fast food restaurant subclasses.

\section{Discussion}

We presented nutrition environment measures of grocery stores, convenience stores, full-service restaurants, and fast-food restaurants located in towns in which Delta Healthy Sprouts participants resided. To our knowledge, this is the first study to directly compare nutrition environment measures among these 4 classes of food outlets in the rural Lower Mississippi Delta. Results indicate that nutrition environments may not have been conducive to effecting positive dietary changes in this cohort of rural, Southern, primarily African American women. Of the 4 food outlet classes, grocery stores had the most healthful nutrition environments. However, they only had $54 \%$ of the maximum score on average, which qualitatively equates to a failing grade on a 10-point grading scale. Fast food restaurants had the least healthful nutrition en- vironments, having less than $10 \%$ of the maximum score on average, indicating that few if any healthful options were available at these outlets. Grocery stores also outperformed convenience stores on the availability and price scales, although again, both classes of outlets scored below $65 \%$ and $30 \%$, respectively, of the maximum scores on average. These results indicate that availability of healthful foods was low, and the price of more healthful foods did not compare favorably with the price of less healthful foods. Fullservice restaurants outperformed fast food restaurants on the healthful options scale, but the reverse was true for the children's menu scale, for which fast food restaurants outperformed full-service restaurants. Again, scores were not optimal, achieving failing grades of less than $35 \%$ of maximum scores. Thus, although some classes of food outlets did outperform others, the nutrition environments of all classes were poor and need improvement to facilitate healthful food choices for residents in these communities.

In a study conducted in Alabama's Black Belt region, mean NEMS-S total scores were 30 for grocery stores and 7 for convenience stores (possible range, -9 to 54) (24), similar to the scores in our study (31 and 8, respectively). Mean NEMS-S total scores were higher for grocery stores and convenience stores (36 and 13, respectively; possible range, -9 to 54) in a rural Minnesota community than in our study (25). Conversely, the mean NEMS-S total score (24; possible range, -9 to 54) was lower for grocery stores located in rural Montana counties, where half the stores measured were on an Indian reservation (26), than for grocery stores in our study. Mean NEMS-S total scores for grocery stores located in rural Washington towns varied from 15 to 35 (possible range, -8 to 62 ), whereas mean total scores for convenience stores varied from 3 to 4 (possible range, -8 to 62) (26). Collectively, results from these studies suggest that the retail nutrition environment in the rural United States is uniformly low; grocery and convenience stores score no more than two-thirds to less than one-quarter of maximum points for indicators of healthful nutrition environments.

Ko and colleagues (27) reported NEMS-R total scores for restaurants located in rural Washington towns; means varied from 4 to 23 for full-service restaurants and from 8 to 19 for fast food restaurants (possible range, -8 to 72 ). Proportionally, mean scores for rural Washington restaurants (0.05-0.32 for full-service, 0.11-0.26 for fast food) were somewhat similar to scores in our study (0.21 for full-service subclass, $0.03-0.19$ for fast food subclass). Although nutrition environments of restaurants were measured in the rural Minnesota community (25), the authors did not report total or scale scores, so we cannot make direct comparisons with our study results. Pereira and colleagues noted that findings were mixed on whether full-service or fast food restaurants had healthier practices (25), similar to our findings that full-service

\footnotetext{
The opinions expressed by authors contributing to this journal do not necessarily reflect the opinions of the U.S. Department of Health and Human Services, the Public Health Service, the Centers for Disease Control and Prevention, or the authors' affiliated institutions.
} 
restaurants scored significantly higher than fast food restaurants on the healthful options scale but significantly lower on the children's menu scale. Results from these studies suggest that nutrition environments of restaurants located in rural communities are suboptimal.

Taken together, these results suggest that behavioral interventions targeting dietary habits of residents of rural communities will not be successful or have long-lasting effects without concurrent changes in local food environments. Retail food environments at both the community level (eg, presence of supermarkets) and the consumer level (eg, healthful affordable foods in convenience stores) are promising venues for effecting positive change in nutrition environments (28). However, results from our study suggest that the presence of grocery stores with suboptimal nutrition environments are not sufficient to improve the diet quality of community residents, because the percentage of participants with passing scores who resided in towns with 4 or 5 grocery stores (11\%) was approximately equal to that of participants who resided in towns with 0 or 1 grocery stores $(12 \%)$.

Additionally, all the towns in which participants resided contained at least 1 convenience store or fast food establishment, food outlets with the poorest nutrition environments. Thus, improving the nutrition environment of convenience stores and fast food establishments as well as teaching rural residents how to navigate in suboptimal food environments to make healthful food choices may prove more efficacious than improving access to grocery stores.

Nutrition environments of restaurants also should be targeted, given the increasing percentages of the population eating away from home, particularly at fast food restaurants (29). A rural communitywide program designed to improve nutrition environments of restaurants was successful at increasing healthful practices of restaurants enrolled in the program as well as restaurants that chose not to enroll (30). Concentrated efforts to improve access and availability within the rural food landscape is becoming increasingly important. It is essential that community partners leverage both public and private funding, such as that provided by the Healthy Food Financing Initiative and the Mid South Healthy Food Initiative, both of which work to increase or expand access to healthy foods in underserved communities. In the absence of environmental changes, it may be necessary to teach residents of underserved communities how to navigate their suboptimal nutrition environments to make more healthful food choices, thereby improving the quality of their diet.

Strengths of our study include the use of validated and objective tools to measure the nutrition environments of rural towns in the Lower Mississippi Delta, the relatively large number of food outlets measured, and the population studied - African American children and adults living in the rural South - who are at increased risk for poor dietary habits (31). Limitations include the nonrandom selection and small number of towns measured; these limitations may restrict the generalizability of the study's results. Some components of the food environment (eg, farmers markets, roadside stands, vending machines) were not included. Additionally, our study results may not accurately reflect the nutrition environments of Delta Healthy Sprouts participants because of temporal differences (ie, the Delta Food Outlets was conducted after Delta Healthy Sprouts was completed). Despite these limitations, this study provides unique and valuable contributions on the potential effects of nutrition environment exposure on health. Additional analytic efforts will include the determination of food outlet clustering in these towns, particularly in relation to proximity to participants' residences.

The food outlets located in the Lower Mississippi Delta towns included in this study scored low on nutrition environment measures associated with healthful eating. Although behavioral interventions designed to bring about positive changes in the dietary habits of rural residents are needed, effects may be minimal or not sustainable if environmental supports, such as food outlets with an abundance of healthful food choices, are not available.

\section{Acknowledgments}

The authors thank Debra Johnson and Donna Ransome for their research support. This research was funded by the USDA Agricultural Research Service (Project 6001-51000-004-00D). The findings and conclusions in this article are those of the authors and should not be construed to represent any official USDA or US government determination or policy. No copyrighted materials were used in this study and the copyrighted NEMS surveys/tools/ instruments are freely available for download and use.

\section{Author Information}

Corresponding Author: Jessica L. Thomson, PhD, USDA Agricultural Research Service, 141 Experiment Station Rd, Stoneville, MS 38776. Telephone: 225-892-3662. Email: jessica.thomson@usda.gov.

Author Affiliations: ${ }^{1}$ US Department of Agriculture, Agricultural Research Service, Stoneville, Mississippi. ${ }^{2}$ Department of Family and Consumer Sciences, University of Central Arkansas, Conway, Arkansas.

The opinions expressed by authors contributing to this journal do not necessarily reflect the opinions of the U.S. Department of Health and Human Services, the Public Health Service, the Centers for Disease Control and Prevention, or the authors' affiliated institutions. 


\section{References}

1. Gennuso KP, Jovaag A, Catlin BB, Rodock M, Park H. Assessment of factors contributing to health outcomes in the eight states of the Mississippi Delta region. Prev Chronic Dis 2016;13:E33.

2. Rifas-Shiman SL, Rich-Edwards JW, Kleinman KP, Oken E, Gillman MW. Dietary quality during pregnancy varies by maternal characteristics in Project Viva: a US cohort. J Am Diet Assoc 2009;109(6):1004-11.

3. King JC. The risk of maternal nutritional depletion and poor outcomes increases in early or closely spaced pregnancies. $\mathrm{J}$ Nutr 2003;133(5,Suppl 2):1732S-6S.

4. Smith BL, Sandlin AT, Bird TM, Steelman SC, Magann EF. Maternal mortality in the Mississippi Delta region. South Med J 2014;107(5):275-9.

5. Bhutta ZA, Das JK, Rizvi A, Gaffey MF, Walker N, Horton S, et al.; Lancet Nutrition Interventions Review Group, the Maternal and Child Nutrition Study Group. Evidence-based interventions for improvement of maternal and child nutrition: what can be done and at what cost? Lancet 2013; 382(9890):452-77.

6. US Department of Health and Human Services, US Department of Agriculture. 2015-2020 Dietary Guidelines for Americans. Washington (DC): Office of Disease Prevention and Health Promotion; 2015.

7. Cohen B, Andrews M, Kantor LS. Community food security assessment toolkit. Washington (DC): US Department of Agriculture, Food Assistance and Nutrition Research Program; 2002. https://www.ers.usda.gov/publications/pub-details/ ?pubid=43179. Accessed January 7, 2020.

8. Laraia BA, Siega-Riz AM, Kaufman JS, Jones SJ. Proximity of supermarkets is positively associated with diet quality index for pregnancy. Prev Med 2004;39(5):869-75.

9. Rose D, Richards R. Food store access and household fruit and vegetable use among participants in the US Food Stamp Program. Public Health Nutr 2004;7(8):1081-8.

10. Thomson JL, Tussing-Humphreys LM, Goodman MH. Delta Healthy Sprouts: a randomized comparative effectiveness trial to promote maternal weight control and reduce childhood obesity in the Mississippi Delta. Contemp Clin Trials 2014; 38(1):82-91.

11. Tussing-Humphreys LM, Thomson JL, Goodman MH, Olender S. Maternal diet quality and nutrient intake in the gestational period: results from the Delta Healthy Sprouts comparative impact trial. Matern Health Neonatol Perinatol 2016;2(1):8.
12. Thomson JL, Tussing-Humphreys LM, Landry AS, Goodman $\mathrm{MH}$. No improvements in postnatal dietary outcomes were observed in a two-arm, randomized, controlled, comparative impact trial among rural, Southern, African-American women. J Acad Nutr Diet 2018;118(7):1196-207.

13. Tussing-Humphreys L, Thomson JL, Goodman M, Landry A. Enhanced vs standard Parents as Teacher curriculum on factors related to infant feeding among African American women. South Med J 2019;112(10):512-9.

14. US Department of Agriculture Food and Nutrition Service. Where can I use SNAP EBT? https://www.fns.usda.gov/snap/ retailerlocator. Accessed May 23, 2018.

15. Mississippi State Department of Health. Restaurant and food facility inspections. https://msdh.ms.gov/msdhsite/_static/ 43,1911,231,203.html. Accessed May 23, 2018.

16.b2 b Biz.com. B 2 B Y ellowpages.com. https:// www.b2byellowpages.com. Accessed May 23, 2018.

17. US Department of Agriculture Economic Research Service. Food environment atlas. https://www.ers.usda.gov/dataproducts/food-environment-atlas/. Accessed August 12, 2019.

18. The University of Pennsylvania. Nutrition Environment Measures Survey. http://www.med.upenn.edu/nems/ measures.shtml. Accessed May 23, 2018.

19. Glanz K, Sallis JF, Saelens BE, Frank LD. Nutrition Environment Measures Survey in stores (NEMS-S): development and evaluation. Am J Prev Med 2007; 32(4):282-9.

20. Cavanaugh E, Mallya G, Brensinger C, Tierney A, Glanz K. Nutrition environments in corner stores in Philadelphia. Prev Med 2013;56(2):149-51.

21. Saelens BE, Glanz K, Sallis JF, Frank LD. Nutrition Environment Measures Study in restaurants (NEMS-R): development and evaluation. Am J Prev Med 2007; 32(4):273-81.

22. Nguyen PK, Lin S, Heidenreich P. A systematic comparison of sugar content in low-fat vs regular versions of food. Nutr Diabetes 2016;6(1):e193.

23. US Census Bureau. 2012-2016 American Community Survey 5-year estimates. https://www.census.gov/acs/www/data/datatables-and-tools/data-profiles/2016. Accessed July 1, 2019.

24. Shikany JM, Carson TL, Hardy CM, Li Y, Sterling S, Hardy S, et al. Assessment of the nutrition environment in rural counties in the Deep South. J Nutr Sci 2018;7:e27.

25. Pereira RF, Sidebottom AC, Boucher JL, Lindberg R, Werner $\mathrm{R}$. Assessing the food environment of a rural community: baseline findings from the heart of New Ulm project, Minnesota, 2010-2011. Prev Chronic Dis 2014;11:E36.

\footnotetext{
The opinions expressed by authors contributing to this journal do not necessarily reflect the opinions of the U.S. Department of Health and Human Services, the Public Health Service, the Centers for Disease Control and Prevention, or the authors' affiliated institutions.
} 
26. Byker Shanks C, Ahmed S, Smith T, Houghtaling B, Jenkins M, Margetts M, et al. Availability, price, and quality of fruits and vegetables in 12 rural Montana counties, 2014. Prev Chronic Dis 2015;12:E128.

27. Ko LK, Enzler C, Perry CK, Rodriguez E, Mariscal N, Linde $\mathrm{S}$, et al. Food availability and food access in rural agricultural communities: use of mixed methods. BMC Public Health 2018;18(1):634.

28. Story M, Kaphingst KM, Robinson-O'Brien R, Glanz K. Creating healthy food and eating environments: policy and environmental approaches. Annu Rev Public Health 2008; 29(1):253-72.

29. Briefel RR, Johnson CL. Secular trends in dietary intake in the United States. Annu Rev Nutr 2004;24(1):401-31.

30. Lindberg R, Sidebottom AC, McCool B, Pereira RF, Sillah A, Boucher JL. Changing the restaurant food environment to improve cardiovascular health in a rural community: implementation and evaluation of the Heart of New Ulm restaurant programme. Public Health Nutr 2018; 21(5):992-1001.

31. Hiza HA, Casavale KO, Guenther PM, Davis CA. Diet quality of Americans differs by age, sex, race/ethnicity, income, and education level. J Acad Nutr Diet 2013;113(2):297-306. 


\section{Tables}

Table 1. Differences Between the Original Scoring Algorithms of the Nutrition Environment Measures and the Revised Scoring Algorithms Used for the Delta Food Outlets Study, 2016-2018

\begin{tabular}{|c|c|c|}
\hline \multirow[b]{2}{*}{ Scale/Item } & \multicolumn{2}{|c|}{ Points } \\
\hline & Original & Revised \\
\hline \multicolumn{3}{|c|}{ Grocery Stores } \\
\hline \multicolumn{3}{|l|}{ Availability } \\
\hline \multirow[t]{2}{*}{ Frozen dinners } & \multirow[t]{2}{*}{1 or 2 reduced-fat types available $=1$ point } & 2 reduced-fat types available $=2$ points \\
\hline & & 1 reduced-fat type available $=1$ point \\
\hline Beverages & Diet soda available $=1$ point & Bottled water available $=1$ point \\
\hline Cereal & No points for availability of $>2$ lower-sugar varieties & $>2$ Lower-sugar varieties available $=1$ point \\
\hline Total & Possible range, 0 to 30 points & Possible range, 0 to 31 points \\
\hline \multicolumn{3}{|l|}{ Price } \\
\hline Frozen dinners & No points for equal prices of low-fat and regular-fat dinners & Equal prices for low-fat and regular-fat dinners $=1$ point \\
\hline Baked goods & No points for equal prices of low-fat and regular-fat goods & Equal prices for low-fat and regular-fat goods $=1$ point \\
\hline \multirow[t]{5}{*}{ Beverages } & \multirow[t]{5}{*}{ Lower price for diet soda than for regular soda $=2$ points } & Lower price for water than for regular soda $=2$ points \\
\hline & & Equal prices for water and regular soda $=1$ point \\
\hline & & Higher price for water than for regular soda $=-1$ point \\
\hline & & Lower price for $100 \%$ juice than for juice drink $=2$ points \\
\hline & & Equal prices for $100 \%$ juice and juice drink = 1 point \\
\hline Bread & $\begin{array}{l}\text { No points for equal prices of whole-wheat bread and } \\
\text { refined-grain bread }\end{array}$ & $\begin{array}{l}\text { Equal prices for whole-wheat bread and refined-grain bread = } \\
1 \text { point }\end{array}$ \\
\hline Baked chips & No points for equal prices of baked chips and regular chips & Equal prices for baked chips and regular chips $=1$ point \\
\hline Cereal & $\begin{array}{l}\text { No points for equal prices of lower-sugar cereal and higher- } \\
\text { sugar cereal }\end{array}$ & $\begin{array}{l}\text { Equal prices for lower-sugar cereal and higher-sugar cereal = } \\
1 \text { point }\end{array}$ \\
\hline Total & Possible range, -9 to 18 points & Possible range, -10 to 20 points \\
\hline Quality & Possible range, 0 to 6 points & Possible range, 0 to 6 points (no change from original) \\
\hline Total & Possible range, -9 to 54 points & Possible range, -10 to 57 points \\
\hline \multicolumn{3}{|c|}{ Convenience Stores } \\
\hline \multicolumn{3}{|l|}{ Availability } \\
\hline \multirow[t]{2}{*}{ Ground beef } & 2 or 3 Varieties $<10 \%$ fat $=1$ point & \multirow[t]{2}{*}{$\geq 1$ variety $<10 \%$ fat $=2$ points } \\
\hline & $>3$ Varieties $<10 \%$ fat $=2$ points & \\
\hline \multirow[t]{2}{*}{ Beverages } & Diet soda available $=1$ point & \multirow[t]{2}{*}{ Bottled water available $=1$ point } \\
\hline & $\begin{array}{l}\text { Non-carbonated, no-calorie or low-calorie available }=1 \\
\text { point }\end{array}$ & \\
\hline 100-Calorie snacks & Available $=2$ points & Available $=0$ points \\
\hline Cereal & No points for $>2$ lower-sugar varieties & $>2$ Lower-sugar varieties = 1 point \\
\hline Total & Possible range, 0 to 34 points & Possible range, 0 to 31 points \\
\hline Price & & \\
\hline
\end{tabular}

a Without added sugar.

${ }^{\mathrm{b}}$ Nonfried and without added sauce.

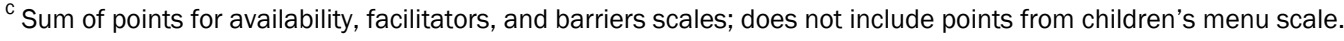

The opinions expressed by authors contributing to this journal do not necessarily reflect the opinions of the U.S. Department of Health and Human Services, the Public Health Service, the Centers for Disease Control and Prevention, or the authors' affiliated institutions. 
(continued)

Table 1. Differences Between the Original Scoring Algorithms of the Nutrition Environment Measures and the Revised Scoring Algorithms Used for the Delta Food Outlets Study, 2016-2018

\begin{tabular}{|c|c|c|}
\hline \multirow[b]{2}{*}{ Scale/Item } & \multicolumn{2}{|c|}{ Points } \\
\hline & Original & Revised \\
\hline Ground beef & $\begin{array}{l}\text { No points for equal prices of lower-fat ground beef and } \\
\text { higher-fat ground beef }\end{array}$ & $\begin{array}{l}\text { Equal prices for lower-fat ground beef and higher-fat ground } \\
\text { beef = } 1 \text { point }\end{array}$ \\
\hline Hot dogs & $\begin{array}{l}\text { No points for equal prices of lower-fat hot dogs and higher- } \\
\text { fat hot dogs }\end{array}$ & $\begin{array}{l}\text { Equal prices for lower-fat hot dogs and higher-fat hot dogs }=1 \\
\text { point }\end{array}$ \\
\hline Frozen dinners & $\begin{array}{l}\text { No points for equal prices of lower-fat dinners and higher- } \\
\text { fat dinners }\end{array}$ & $\begin{array}{l}\text { Equal prices for lower-fat dinners and regular-fat dinners = } 1 \\
\text { point }\end{array}$ \\
\hline Baked goods & $\begin{array}{l}\text { No points for equal prices of lower-fat goods and higher-fat } \\
\text { goods }\end{array}$ & $\begin{array}{l}\text { Equal prices for lower-fat goods and regular-fat goods = } 1 \\
\text { point }\end{array}$ \\
\hline \multirow[t]{3}{*}{ Beverages } & Lower price for diet soda than for regular soda $=2$ points & Lower price for water than for $100 \%$ juice $=2$ points \\
\hline & \multirow[t]{2}{*}{ No points for equal prices of water and $100 \%$ juice } & Equal prices for water and $100 \%$ juice $=1$ point \\
\hline & & Higher price for water than for $100 \%$ juice $=-1$ point \\
\hline Bread & $\begin{array}{l}\text { No points for equal prices of whole-wheat bread and } \\
\text { refined-grain bread }\end{array}$ & $\begin{array}{l}\text { Equal prices for whole-wheat bread and refined-grain bread = } \\
1 \text { point }\end{array}$ \\
\hline Baked chips & No points for equal prices of baked chips and regular chips & Equal prices for baked chips and regular chips $=1$ point \\
\hline Cereal & $\begin{array}{l}\text { No points for equal prices of lower-sugar cereal and higher- } \\
\text { sugar cereal }\end{array}$ & $\begin{array}{l}\text { Equal prices for lower-sugar cereal and higher-sugar cereal = } \\
1 \text { point }\end{array}$ \\
\hline Total & Possible range, -9 to 18 points & Possible range, -9 to 20 points \\
\hline Quality & Possible range, 0 to 6 points & Possible range, 0 to 6 points (no change from original) \\
\hline Total & Possible range, -9 to 58 points & Possible range, -9 to 57 points \\
\hline \multicolumn{3}{|c|}{ Restaurants } \\
\hline \multicolumn{3}{|l|}{ Availability of healthful options } \\
\hline Low-fat or fat-free dressing & 1 to 3 Choices $=1$ to 3 points & No points \\
\hline Fruit $^{\mathrm{a}}$ & $\geq 1$ choice $=1$ point & $\begin{array}{l}1 \text { choice }=1 \text { point, } 2 \text { to } 4 \text { choices }=2 \text { points, } \geq 5 \text { choices }=3 \\
\text { points }\end{array}$ \\
\hline Vegetable $^{\mathrm{b}}$ & $\geq 1$ choice $=1$ point & $\begin{array}{l}1 \text { choice = } 1 \text { point, } 2 \text { to } 4 \text { choices }=2 \text { points, } \geq 5 \text { choices }=3 \\
\text { points }\end{array}$ \\
\hline Bottled water & No points for availability & Available $=1$ point \\
\hline Total & Possible range, 0 to 15 points & Possible range, 0 to 17 points \\
\hline \multicolumn{3}{|l|}{ Facilitators for healthful eating } \\
\hline $\begin{array}{l}\text { Menu nutrition information or healthy } \\
\text { entrée identified }\end{array}$ & Presence of either $=1$ point & Presence $=1$ point per facilitator \\
\hline $\begin{array}{l}\text { Signage highlighting healthful options } \\
\text { or healthy eating encouraged }\end{array}$ & Presence of either $=1$ point & Presence $=1$ point per facilitator \\
\hline Total & Possible range, 0 to 8 points & Possible range, 0 to 10 points \\
\hline \multicolumn{3}{|l|}{ Barriers to healthful eating } \\
\hline Shared entrée & No points for extra cost & Extra cost $=-1$ point \\
\hline $\begin{array}{l}\text { Signage, unhealthful eating } \\
\text { encouraged or overeating encouraged }\end{array}$ & Presence of either $=-1$ point & Presence $=-1$ point per barrier \\
\hline Total & Possible range, -5 to 0 points & Possible range, -7 to 0 points \\
\hline
\end{tabular}

a Without added sugar.

${ }^{\mathrm{b}}$ Nonfried and without added sauce.

${ }^{\mathrm{c}}$ Sum of points for availability, facilitators, and barriers scales; does not include points from children's menu scale. 
(continued)

Table 1. Differences Between the Original Scoring Algorithms of the Nutrition Environment Measures and the Revised Scoring Algorithms Used for the Delta Food Outlets Study, 2016-2018

\begin{tabular}{|l|l|l|}
\hline \multirow{2}{*}{ Scale/Item } & \multicolumn{1}{|c|}{ Points } \\
\cline { 2 - 3 } & \multicolumn{1}{|c|}{ Original } & \multicolumn{1}{c|}{ Revised } \\
\hline Children's menu & Possible range, -3 to 9 points & Possible range, -3 to 9 points (no change from original) \\
\hline Total $^{c}$ & Possible range, -5 to 21 points & Possible range $=-7$ to 27 points \\
\hline
\end{tabular}

${ }^{a}$ Without added sugar.

${ }^{\mathrm{b}}$ Nonfried and without added sauce.

${ }^{\mathrm{c}}$ Sum of points for availability, facilitators, and barriers scales; does not include points from children's menu scale. 
Table 2. Characteristics of Towns Included in the Delta Food Outlet Study, 2016-2018

\begin{tabular}{|c|c|c|c|c|c|c|}
\hline Characteristic & Town 1 & Town 2 & Town 3 & Town 4 & Town 5 & Total \\
\hline Population size ${ }^{a}$ & 32,612 & 12,346 & 4,254 & 2,484 & 1,750 & - \\
\hline Percentage African American $^{a}$ & 80 & 49 & 69 & 86 & 91 & - \\
\hline Percentage living below federal poverty level ${ }^{a}$ & 36 & 29 & 32 & 41 & 51 & - \\
\hline \multicolumn{7}{|l|}{ No. of food outlets } \\
\hline Grocery store & 5 & 4 & 1 & 1 & 0 & 11 \\
\hline Convenience store & 48 & 18 & 10 & 6 & 4 & 86 \\
\hline Full-service restaurant & 28 & 16 & 5 & 1 & 0 & 50 \\
\hline Fast food restaurant & 60 & 40 & 8 & 7 & 4 & 119 \\
\hline
\end{tabular}

${ }^{\text {a }}$ 2012-2016 American Community Survey 5-year estimates (23). 
Table 3. Nutrition Environment Measures Survey Scores for Food Outlets $(\mathrm{N}=266)$ by Class and Subclass of Food Outlet, Delta Food Outlets Study, $2016-2018$

\begin{tabular}{|c|c|c|c|c|c|}
\hline \multirow[b]{2}{*}{$\begin{array}{l}\text { Class or Subclass of Food Outlet and Type of } \\
\text { Scale }\end{array}$} & \multirow[b]{2}{*}{$\begin{array}{l}\text { Possible Score } \\
\text { Range }\end{array}$} & \multirow[b]{2}{*}{ No. of Outlets } & \multicolumn{2}{|c|}{ Original Score } & \multirow[b]{2}{*}{$\begin{array}{l}\text { Ratio Score, Least Squares } \\
\text { Mean }(95 \% \mathrm{Cl})^{\mathrm{a}}\end{array}$} \\
\hline & & & Mean (SD) & $\underset{\mathrm{m}}{\operatorname{Minimum}}$ & \\
\hline \multicolumn{6}{|c|}{ Total } \\
\hline \multicolumn{6}{|l|}{ Class } \\
\hline Grocery store & -10 to 57 & 11 & $30.5(7.5)$ & 22 to 41 & $0.54(0.47 \text { to } 0.60)^{b}$ \\
\hline Convenience store & -9 to 57 & 86 & $8.1(3.2)$ & 2 to 14 & $0.16(0.13 \text { to } 0.19)^{\mathrm{c}}$ \\
\hline Full-service restaurant & -7 to 27 & 50 & $5.6(3.5)$ & -2 to 18 & $0.21(0.18 \text { to } 0.24)^{\mathrm{c}}$ \\
\hline Fast food restaurant & -7 to 27 & 119 & $3.9(4.0)$ & -2 to 19 & $0.08(0.05 \text { to } 0.12)^{d}$ \\
\hline \multicolumn{6}{|l|}{ Convenience store subclass } \\
\hline Corner store & -9 to 57 & 21 & $6.6(2.9)$ & 2 to 14 & $0.12(0.07 \text { to } 0.16)^{b}$ \\
\hline Gas station & -9 to 57 & 40 & $7.2(2.8)$ & 2 to 14 & $0.13(0.09 \text { to } 0.16)^{b}$ \\
\hline National chain dollar store & -9 to 57 & 21 & $10.7(2.3)$ & 4 to 14 & $0.19(0.14 \text { to } 0.24)^{b}$ \\
\hline National chain pharmacy & -9 to 57 & 4 & $12.0(2.5)$ & 9 to 14 & $0.21(0.10 \text { to } 0.32)^{b}$ \\
\hline \multicolumn{6}{|l|}{ Fast food subclass } \\
\hline Restaurant stand-alone & -7 to 27 & 81 & $5.2(4.1)$ & -1 to 19 & $0.19(0.17 \text { to } 0.22)^{b}$ \\
\hline Grocery store delicatessen ${ }^{\mathrm{e}}$ & -7 to 27 & 8 & $1.8(1.9)$ & -1 to 5 & $0.06(-0.01 \text { to } 0.14)^{\mathrm{c}}$ \\
\hline Corner store $^{f}$ & -7 to 27 & 5 & $0.8(1.9)$ & -1 to 4 & $0.03(-0.07 \text { to } 0.13)^{\mathrm{C}}$ \\
\hline Gas station $^{f}$ & -7 to 27 & 25 & $1.0(1.8)$ & -2 to 5 & $0.04(-0.01 \text { to } 0.08)^{c}$ \\
\hline \multicolumn{6}{|c|}{ Type of Scale } \\
\hline \multicolumn{6}{|l|}{ Availability scale } \\
\hline Grocery store & 0 to 31 & 11 & $19.6(5.7)$ & 12 to 28 & $0.63(0.58 \text { to } 0.68)^{b}$ \\
\hline Convenience store & 0 to 31 & 86 & $5.6(3.0)$ & 1 to 11 & $0.21(0.19 \text { to } 0.23)^{\mathrm{c}}$ \\
\hline \multicolumn{6}{|l|}{ Convenience store subclass } \\
\hline Corner store & 0 to 31 & 21 & $3.9(1.5)$ & 1 to 8 & $0.12(0.10 \text { to } 0.15)^{b}$ \\
\hline Gas station & 0 to 31 & 40 & $4.1(1.5)$ & 1 to 7 & $0.13(0.11 \text { to } 0.15)^{b}$ \\
\hline National chain dollar store & 0 to 31 & 21 & $9.6(1.8)$ & 4 to 11 & $0.31(0.28 \text { to } 0.35)^{c}$ \\
\hline National chain pharmacy & 0 to 31 & 4 & $10.0(1.4)$ & 8 to 11 & $0.32(0.25 \text { to } 0.41)^{c}$ \\
\hline \multicolumn{6}{|l|}{ Price scale } \\
\hline Grocery store & -10 to 20 & 11 & $5.0(3.5)$ & -1 to 9 & $0.25(0.20 \text { to } 0.30)^{b}$ \\
\hline Convenience store & -9 to 20 & 86 & $2.3(1.6)$ & -2 to 5 & $0.10(0.08 \text { to } 0.13)^{c}$ \\
\hline \multicolumn{6}{|l|}{ Convenience store subclass } \\
\hline Corner store & -9 to 20 & 21 & $2.3(1.9)$ & 0 to 4 & $0.11(0.08 \text { to } 0.15)^{b, c}$ \\
\hline
\end{tabular}

Abbreviations: $\mathrm{Cl}$, confidence interval; SD, standard deviation.

${ }^{a}$ Nutrition Environment Measures Survey scores were translated into ratio scores by dividing the score for each food outlet by the maximum score possible. Least squares means and associated $95 \%$ confidence intervals were computed from the general linear models used to test for significant differences among classes and subclasses of food outlets.

${ }_{b, c, d}$ Food outlet classes or subclasses with different letters are significantly different from one another at $P<.003$ based on general linear model results. Food outlet classes or subclasses with the same letters are not significantly different from one another.

${ }^{\mathrm{e}}$ Dual classification as grocery store.

${ }^{f}$ Dual classification as convenience store.

${ }^{\mathrm{g}}$ Differences in ratio score among classes and subclasses were not significant.

${ }^{\mathrm{h}}$ None of the fast food restaurant subclasses had children's menus except stand-alone restaurants.

(continued on next page)

The opinions expressed by authors contributing to this journal do not necessarily reflect the opinions of the U.S. Department of Health and Human Services, the Public Health Service, the Centers for Disease Control and Prevention, or the authors' affiliated institutions. 
(continued)

Table 3. Nutrition Environment Measures Survey Scores for Food Outlets $(\mathrm{N}=266)$ by Class and Subclass of Food Outlet, Delta Food Outlets Study, $2016-2018$

\begin{tabular}{|c|c|c|c|c|c|}
\hline \multirow[b]{2}{*}{$\begin{array}{l}\text { Class or Subclass of Food Outlet and Type of } \\
\text { Scale }\end{array}$} & \multirow[b]{2}{*}{$\begin{array}{l}\text { Possible Score } \\
\text { Range }\end{array}$} & \multirow[b]{2}{*}{ No. of Outlets } & \multicolumn{2}{|c|}{ Original Score } & \multirow[b]{2}{*}{$\begin{array}{l}\text { Ratio Score, Least Squares } \\
\text { Mean }(95 \% \mathrm{Cl})^{2}\end{array}$} \\
\hline & & & Mean (SD) & $\underset{\mathrm{m}}{\operatorname{Minimum} \text {-Maximu }}$ & \\
\hline Gas station & -9 to 20 & 40 & $2.9(1.3)$ & 0 to 5 & $0.14(0.12 \text { to } 0.17)^{b}$ \\
\hline National chain dollar store & -9 to 20 & 21 & $1.1(1.5)$ & -1 to 4 & $0.05(0.02 \text { to } 0.09)^{\mathrm{c}}$ \\
\hline National chain pharmacy & -9 to 20 & 4 & $2.0(2.7)$ & -2 to 4 & $0.10(0.01 \text { to } 0.19)^{b, c}$ \\
\hline \multicolumn{6}{|l|}{ Healthful options scale } \\
\hline Full-service restaurant & 0 to 17 & 50 & $5.5(2.7)$ & 1 to 14 & $0.32(0.28 \text { to } 0.37)^{b}$ \\
\hline Fast food restaurant & 0 to 17 & 119 & $3.7(3.1)$ & 0 to 12 & $0.13(0.08 \text { to } 0.18)^{\mathrm{C}}$ \\
\hline \multicolumn{6}{|l|}{ Fast food subclass } \\
\hline Restaurant stand-alone & 0 to 17 & 81 & $4.8(3.1)$ & 0 to 12 & $0.28(0.25 \text { to } 0.32)^{b}$ \\
\hline Grocery store delicatessen ${ }^{e}$ & 0 to 17 & 8 & $1.8(1.2)$ & 0 to 3 & $0.10(-0.01 \text { to } 0.21)^{\mathrm{C}}$ \\
\hline Corner store $^{f}$ & 0 to 17 & 5 & $0.8(1.3)$ & 0 to 3 & $0.05(-0.03 \text { to } 0.19)^{c}$ \\
\hline Gas station $^{f}$ & 0 to 17 & 25 & $1.4(1.4)$ & 0 to 5 & $0.08(0.02 \text { to } 0.14)^{\mathrm{c}}$ \\
\hline \multicolumn{6}{|l|}{ Facilitators for healthful eating scale ${ }^{g}$} \\
\hline Full-service restaurant & 0 to 10 & 50 & $0.7(1.1)$ & 0 to 6 & - \\
\hline Fast food restaurant & 0 to 10 & 119 & $0.9(1.3)$ & 0 to 7 & - \\
\hline \multicolumn{6}{|l|}{ Fast food subclass } \\
\hline Restaurant stand-alone & 0 to 10 & 81 & $1.2(1.5)$ & 0 to 7 & - \\
\hline Grocery store delicatessen $^{\mathrm{e}}$ & 0 to 10 & 8 & $0.4(0.7)$ & 0 to 2 & - \\
\hline Corner store $^{f}$ & 0 to 10 & 5 & $0.2(0.5)$ & 0 to 1 & - \\
\hline Gas station $^{f}$ & 0 to 10 & 25 & $0.5(0.1)$ & 0 to 2 & - \\
\hline \multicolumn{6}{|l|}{ Barriers to healthful eating scale ${ }^{g}$} \\
\hline Full-service restaurant & -7 to 0 & 50 & $-0.5(0.8)$ & -3 to 0 & - \\
\hline Fast food restaurant & -7 to 0 & 119 & $-0.7(0.9)$ & -3 to 0 & - \\
\hline \multicolumn{6}{|l|}{ Fast food subclass } \\
\hline Restaurant stand-alone & -7 to 0 & 81 & $-0.7(1.0)$ & -3 to 0 & - \\
\hline Grocery store delicatessen $^{\mathrm{e}}$ & -7 to 0 & 8 & $-0.4(0.5)$ & -1 to 0 & - \\
\hline Corner store $^{f}$ & -7 to 0 & 5 & $-0.2(0.5)$ & -1 to 0 & - \\
\hline Gas station $^{f}$ & -7 to 0 & 25 & $-0.8(0.8)$ & -2 to 0 & - \\
\hline \multicolumn{6}{|l|}{ Children's menu scale ${ }^{\mathrm{h}}$} \\
\hline Full-service restaurant & -3 to 9 & 26 & $0.0(1.4)$ & -1 to 4 & $0.00(-0.07 \text { to } 0.07)^{b}$ \\
\hline Fast food restaurant & -3 to 9 & 41 & $1.8(1.7)$ & -2 to 5 & $0.20(0.14 \text { to } 0.25)^{\mathrm{C}}$ \\
\hline
\end{tabular}

Abbreviations: $\mathrm{Cl}$, confidence interval; SD, standard deviation.

${ }^{a}$ Nutrition Environment Measures Survey scores were translated into ratio scores by dividing the score for each food outlet by the maximum score possible. Least squares means and associated 95\% confidence intervals were computed from the general linear models used to test for significant differences among classes and subclasses of food outlets.

${ }_{b, c, d}$ Food outlet classes or subclasses with different letters are significantly different from one another at $P<.003$ based on general linear model results. Food outlet classes or subclasses with the same letters are not significantly different from one another.

${ }^{e}$ Dual classification as grocery store.

${ }^{f}$ Dual classification as convenience store.

${ }^{g}$ Differences in ratio score among classes and subclasses were not significant.

${ }^{\mathrm{h}}$ None of the fast food restaurant subclasses had children's menus except stand-alone restaurants. 